\title{
Rotational Speed Control of Brushless DC Motor Using Genetic Algorithm Optimized PD Controller
}

\author{
Rizqi Andry Ardiansyah *, Edwar Yazid \\ Research Center for Electrical Power and Mechatronics \\ Indonesian Institute of Sciences \\ Jl.Cisitu Sangkuriang 154d/21, 40135 \\ Bandung, Indonesia
}

\begin{abstract}
Controlling the rotational speed of brushless DC (BLDC) motor is an essential task to improve the transient and the steady state performances under loaded condition. Rotational speed control of BLDC motor using genetic algorithm optimized proportional-derivative (PD) controller to form what the so-called the genetic algorithm-PD (GA-PD) controller is proposed in this paper. Control system is realized in a microcontroller namely a $16 \mathrm{MHz}$ Atmega 2560 with an absolute encoder as a position sensor. The effectiveness of the GA-PD controller is tested under constant and varying step functions with the Ziegler-NicholsPD (ZN-PD) controller as a benchmark. Experimental results show that the GA-PD controller has slower speed than the ZN-PD controller, but the latter has overshoot and small oscillations during its steady state condition as a consequent of having a fast rise time.
\end{abstract}

Keywords: Rotational speed, BLDC motor, PD controller, genetic algorithm

\section{INTRODUCTION}

Brushless DC motor (BLDC) has been widely used for many years in many industrial application because of its efficiency and reliability. There has been a massive research interest in the area of modelling and control of BLDC as reported in the literatures. Recent research, for instance, an efficient ANFIS based speed controller for BLDC motor is proposed as in [1]. ANFIS controller is modelled through modified data of the fuzzy tuned PID controller and is simulated under varying speed and load conditions. Control system responses shows that the proposed controller is superior to the classical PI and fuzzy tuned PID controller and fuzzy variable structure controller. Bat algorithm optimized online ANFIS for the same plant is also proposed [2]. Their results show that the proposed controller eliminates the uncertainty problem due to load disturbance and enhance the time domain specifications and performances in all operating conditions. The same algorithm is then enhanced using the same system by proposing a fuzzy online gain tuned windup PID and fuzzy PID supervised ANFIS [3]. The results show that the windup problem can be eliminated and also improve control system performances.

Performance of self-tuning fuzzy PID controller and model reference adaptive control (MRAC) with PID compensator is compared by [4]. The result shows that combination of MRAC with PID control compensator eliminates the overshoots and steady-state error. Comparison between antiwindup PI controller and conventional PI controller in brushless DC motor speed

\footnotetext{
* Corresponding Author. Email: rizqinhood@gmail.com Received: June 29, 2018 ; Revised: December 12, 2018 Accepted: December 19, 2018 ; Published: December 31, 2018 (C) 2018 PPET - LIPI
}

controlling is conducted by [5]. Simulation and experimental results show that the anti-windup PI controller has better anti disturbance ability, less overshoot, and less settling time. Other controller variants such as hybrid fuzzy-PID, PSO-PID and BFPID can be found in references [6]-[10], respectively.

Contribution of this paper is put on the experimental control of BLDC motor by using proportional-derivative (PD) controller which is optimized by genetic algorithm (GA). The experiment is conducted in purpose to optimize the gains of PD controller which is an essential task in controlling the BLDC motor. Control algorithm is realized in a plant that consists of a BLDC as a controlled system, an encoder sensor for position sensor, and an Arduino Atmega 2560 board.

The reminder of this paper is organized as follows: Section 2 describes about the modelling of BLDC motor, followed by the concept of PID controller in Section 3. Model of Genetic Algorithm combined with PD controller is put on Section 4. Section 5 describes the experimental setup and Section 6 presents the experimental results and discussions. Finally, some conclusions are written in Section 7.

\section{MODEL OF BLDC MOTOR}

In this study, KC AXHM5100 Vexta Brushless DC Motor is used. KC AXHM5100 Vexta BLDCM is a brushless dc motor produced by Oriental Motor Corp. This type of motor has a three-phase brushless dc that has schematic diagram can be shown below in Figure 1.

The mathematical model of three-phase BLDC motor with several assumptions has been outlined in [10], but it is revisited here for a concise notation. General voltage equation for the underlying system can be written in a state-space as expressed in (1). 


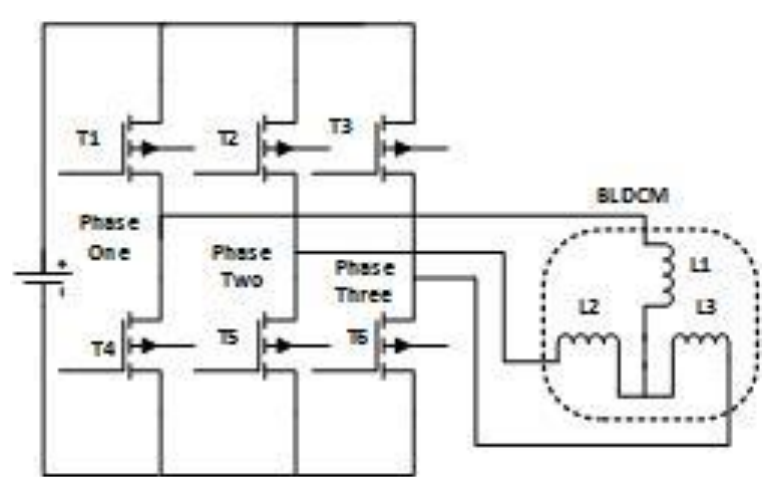

Figure 1. Schematic diagram of three-phase BLDC motor.

$$
\left\{\begin{array}{l}
u_{x} \\
u_{y} \\
u_{z}
\end{array}\right\}=\left[\begin{array}{ccc}
R & 0 & 0 \\
0 & R & 0 \\
0 & 0 & R
\end{array}\right]\left\{\begin{array}{l}
i_{x} \\
i_{y} \\
i_{z}
\end{array}\right\}+\left[\begin{array}{ccc}
L & M & M \\
M & L & M \\
M & L & L
\end{array}\right]\left\{\begin{array}{l}
i_{x} \\
i_{y} \\
i_{z}
\end{array}\right\}+\left\{\begin{array}{l}
e_{x} \\
e_{y} \\
e_{z}
\end{array}\right\}
$$

Terms in (1) can be explained as follows: $u_{x}, u_{y}, u_{z}$ are phase coils voltage $(\mathrm{V}), i_{x}, i_{y}, i_{z}$ are three-phase current from coils stator voltage (A), $e_{x}, e_{y}, e_{z}$ are back EMF (V) and $R$ is phase resistant $(\Omega)$ while $L$ is phase inductance $\mathrm{M}(\mathrm{H})$. The three-phase current at balanced condition is formulated in (2), while the electromagnetic torque is given in (3).

$$
\begin{gathered}
i_{x}+i_{y}+i_{z}=0 \\
T_{e}=\frac{e_{x} i_{x}+e_{y} i_{y}+e_{z} i_{z}}{\omega_{m}}
\end{gathered}
$$

$\omega_{m}$ denotes the mechanical angular speed, which is the variable control. This speed is an essential component in the mechanical torque as shown in (4). By relating the electromagnetic torque in (3) and mechanical torque in (4), the rate of mechanical angular speed is calculated using (5).

$$
\begin{gathered}
T_{m}=J \frac{d \omega_{m}}{d t}+B \omega_{m} \\
\frac{d \omega_{m}}{d t}=\frac{T_{e}-T_{m}}{J}-\frac{B}{J} \omega_{m}
\end{gathered}
$$

Where $J$ and $B$ in Equation 5 are moment inertia and friction coefficient, respectively. By using technical specifications shown in Table 1 [11] and respective chosen parameters, control simulation of BLDC motor can be performed and compared to the experiment in the next section.

TABEL 1

KC AXHM5100 BLDC MOTOR SPECIFICATION

$\begin{array}{lc}\text { Rated Output Power - HP(W) } & 1 / 8(100) \\ \text { Voltage - VDC } & 24+/-10 \% \\ \text { Rated Input Current - A } & 6 \\ \text { Rated Torque (N.m) } & 0.40 \\ \text { Permissible Load Inertia J }\left(10^{-4} \mathrm{~kg} \cdot \mathrm{m}^{2}\right) & 5.6 \\ \text { Speed max (RPM) } & 3000\end{array}$

\section{PID AND GA-PD CONTROLLER}

\section{A. PID Controller}

PID controller is one of the classical closed-loop control systems that has been widely used in many industrial applications for many years due to its simplicity and robustness in the engineering systems. The main principle of PID controller is about to constitute a control action with proportional, integral, and differential gains then choosing the best combination and its corresponding optimal gains in order to control the plant. The control diagram block in discrete time index is shown in Figure 2.

Error of the plant, which is denoted by $e(n)$, can be obtained by differentiating the reference input value $y_{\mathrm{i}}(n)$ and output value $y_{\mathrm{o}}(n)$ as expressed in (6). Error and its derivative are then multiplied with the proportional gain $\left(K_{p}\right)$, integral gain $\left(K_{i}\right)$ and derivative gain $\left(K_{d}\right)$ to form the control action $\left(U_{n}\right)$ which is sent to the plant. Complete expression of control action can be written as shown in (7).

$$
\begin{gathered}
e(n)=y_{i}(n)-y_{o}(n) \\
u(n)=K_{p} e(n)+K_{i} \sum e(n)+K_{d} \Delta e_{T}(n)
\end{gathered}
$$

Under any types of system input, the gains in (7) significantly affect the closed-loop system in Figure 2. Suboptimal gains lead to the system becomes unstable, high overshoot and large steady-state error. The gains must be designed to match the system input (set-point) and the system output by giving the corrective action in terms of control action. Hence, the GA algorithm is employed to optimize those gains.

\section{B. GA-PD Controller}

Optimization process of the gains of PD controller, $K_{p}$ and $K_{d}$ through GA algorithm is depicted in Figure 3. Initial gains, $\left\{K_{p}, K_{d}\right\}$ are created randomly and are called as chromosomes to form one population. Each chromosome in the population is evaluated using following cost function as formulated in (8).

$$
S S E=\sum_{n=1}^{N}\left(\omega_{d}(n)-\omega(n)\right)
$$

Other cost function can be employed, however, the stated equation is regarded sufficient for the underlying plant. Selection is then performed to choose the parents among the chromosomes by using fitness-proportionate selection technique called Roulette Wheel Selection. Crossover and mutation as well as elitism are applied to generate new population (offspring). Next population is generated by applying the fitness-based selection technique. These steps are repeated until maximum number of generations is reached [12]. This sub-process is then combined into the closed-loop control system with PD controller as shown by Figure 4 to form what the so-called GA-PD controller. 


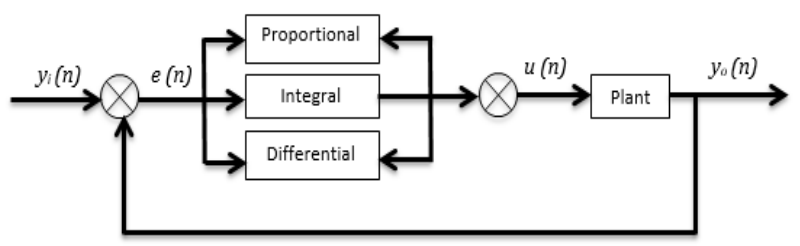

Figure 2. PID control diagram block.

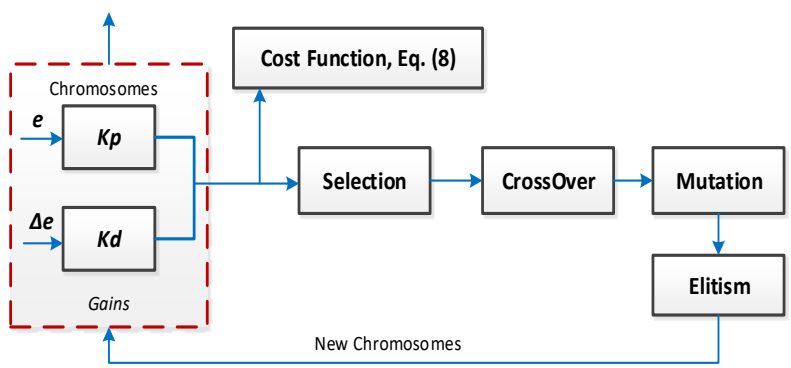

Figure 3. Gains optimization process in GA-PD controller.

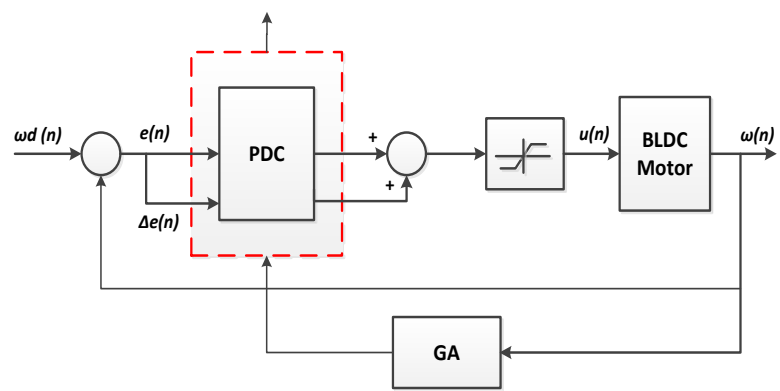

Figure 4. Diagram block of GA-PD controller.

\section{EXPERIMENTAL SETUP}

Experiment is conducted in mechatronic division laboratory, Research Centre for Electrical Power and Mechatronics, Indonesian Institute of Science, where the experimental setup for implementing the proposed GA-PD controller is shown in Figure 5. There are two main electronic circuits used in this experiment, a $16 \mathrm{MHz}$ Atmega 2560 microcontroller unit and a BLDC motor driver unit, while a 3 phases 24 Volt/100 watt AXH Series BLDC motor from Oriental motor as a plant.

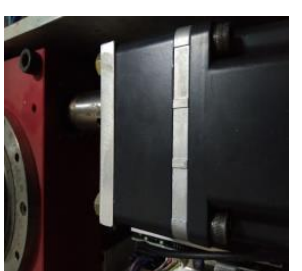

(a)

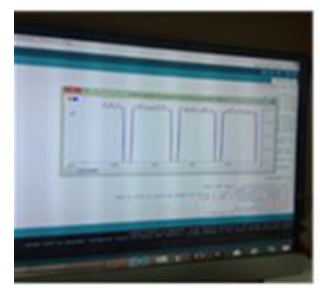

(c)
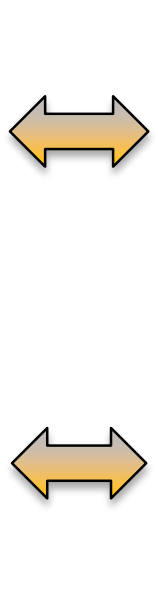

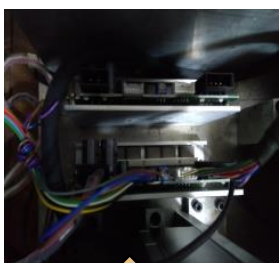

(b)
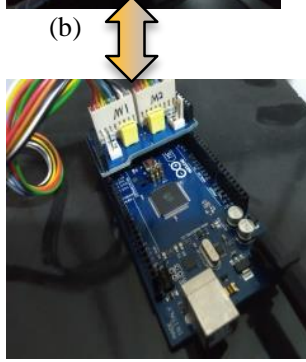

(d)

Figure 5. Experimental setup (a) BLDC motor (b) BLDC driver circuit (c) computer (d) microcontroller.

The 16MHz Atmega 2560 microcontroller unit as a main controller is used to drive the BLDC motor as well as to record the motor speed. The maximum voltage is 24 Volt, and is limited up to 5 Vref Pulse Width Modulation Signal. The internal 30 pulses per revolution rotary encoder sensor is used to measure the motor speed. Before conducting the experiment, the connection of BLDC motor its driver unit must be ensured. Five wire signal pins (Start/Stop, Run/Brake, CW/CCW, EXT Inp, Speed Output) from BLDC motor driver unit is then connected to five pins of microcontroller. External interrupt and timer feature in Atmega 2560 are used to measure the motor speed. In order to record the motor in a database in a computer, a serial communication is used to send the speed data from microcontroller to computer. The sampling rate for the experiment is 50 milliseconds.

\section{RESUlTS AND DISCUSSION}

In this section, performance of the proposed GAPD controller is investigated under two step functions, constant and varying step functions. Other functions such as sinusoidal function are not elaborated in this study. Parameters used in the GA-PD controller are given by 50 individuals in population size of 0.4 for hyper-mutation rate with a crossover rate of 0.65 . GAPD controller is executed in 50 iterations with the interval for the searching space is $0 \leq x \leq 50$ for $\left\{K_{p}, K_{d}\right\}$.

Control performances in time domain are assessed in terms of rise time, settling time, overshoot and peak time and compared. BLDC motor is commanded to track a rotational speed $\omega_{d} \rightarrow 30 \mathrm{rps}$ by giving a constant step function. The control response for time duration of 5 second is shown in Figure 6(a). The figure depicts that the BLDC motor is able to track the commanded speed and all controllers have successfully reached it with respect to time. However, each controller has different performances during the tracking especially for the GA-PD controller. The controller tracks the commanded speed slower than the ZN-PD controller. However, the ZN-PD controller has small oscillations during its steady state condition. This is a consequent of having high gains $\mathrm{ZN}-\mathrm{PD}$ controller as shown by Table 3 .

Hence, it leads to a fast rise time as confirmed by Table 3 and high control action as shown in Figure 6(b). Table 3 also shows that the fast rise time of $\mathrm{ZN}$ PD controller results in overshoot of $6.67 \%$. However, settling time for both controllers is almost similar in this case. Details of performances and the gains of each controller are tabulated in Table 3 and Table 4, respectively.

TABEL 2

PARAMETER OF GA

\section{GA}

Number of iterations

Number of population

50 Selection

50 Crossover rate

Roulette Wheel

Number of optimized

parameters 


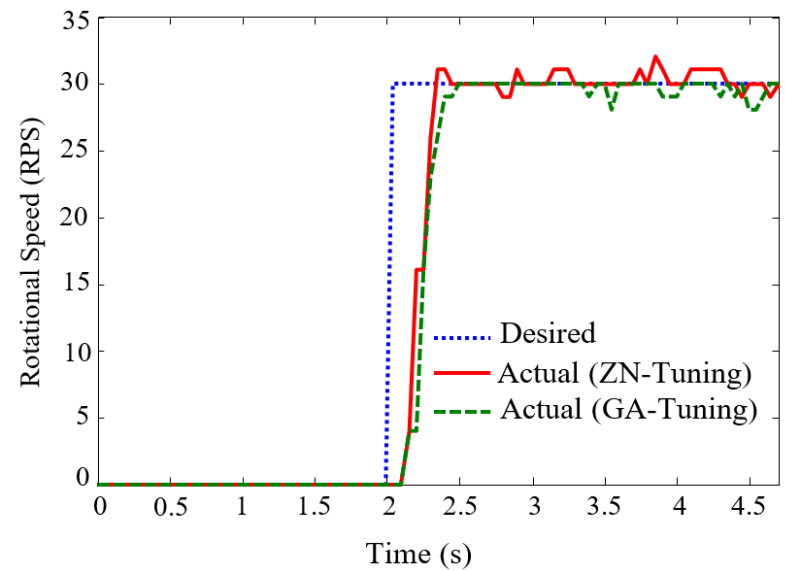

(a)

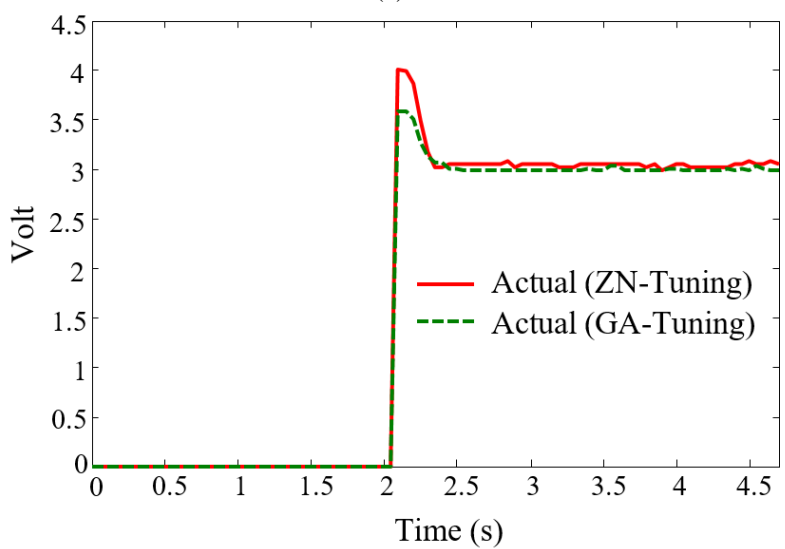

(b)

Figure 6. Constant step function, (a) control response (b) control action.

TABEL 3

CONTROLLER'S PERFORMANCES UNDER CONSTANT STEP FUNCTION

\begin{tabular}{lcc}
\hline Performance & ZN-PD & GA-PD \\
\hline Rise time (s) & 0.17 & 0.23 \\
Settling time (s) & 4.67 & 4.62 \\
Overshoot (\%) & 6.67 & 0 \\
Peak time (s) & 3.85 & 2.5 \\
\hline
\end{tabular}

TABEL 4

GAIN OF CONTROLLERS FOR CONSTANT STEP FUNCTION

\begin{tabular}{lcc}
\hline \multirow{2}{*}{ Controller } & \multicolumn{2}{c}{ Gain } \\
\cline { 2 - 3 } & $\mathrm{P}$ & $\mathrm{D}$ \\
\hline ZN-PD & 1.58 & 0.4 \\
GA-PD & 0.85 & 0.02 \\
\hline
\end{tabular}

In optimizing the gains, PD controller optimized by GA algorithm produces a cost function as shown in Figure 7. It displays the cost function with respect to the number of iterations. As observed, the cost exhibits a gradual convergence and seems like a ladder function as the number of iteration increases. However, the cost function starts to converge after the $-9^{\text {th }}$ iteration and is steady to a certain value. Further, BLDC motor is commanded to track a rotational speed $\omega_{d} \rightarrow 10,20,50$, 40, $30 \mathrm{rps}$ by giving a varying step function. Varying step function represents the varying load condition. The results are shown in Figure 8. Again, the
BLDC motor is able to track the commanded speed and both controllers have successfully tracked it with respect to time. For clarity, control response and action are zoomed at time window of 5-7 s, and shown in Figure 9. Finding results in the constant step function seem similar for this case.

In the time duration, ZN-PD controller has faster rise time than GA-PD controller, where it is $0.08 \mathrm{~s}$ against $0.175 \mathrm{~s}$. However, it generates overshoot of $22.22 \%$. In this case, GA-PD controller again shows it superior against the ZN-PD controller in term of minimum overshoot. This is confirmed by Figure 8 and Table 5. Similar with constant step function, gains resulted from GA-PD controller are lower than ZN-PD controller as shown by Table 6 . It contributes to the fast rise time and high control action of ZN-PD controller as

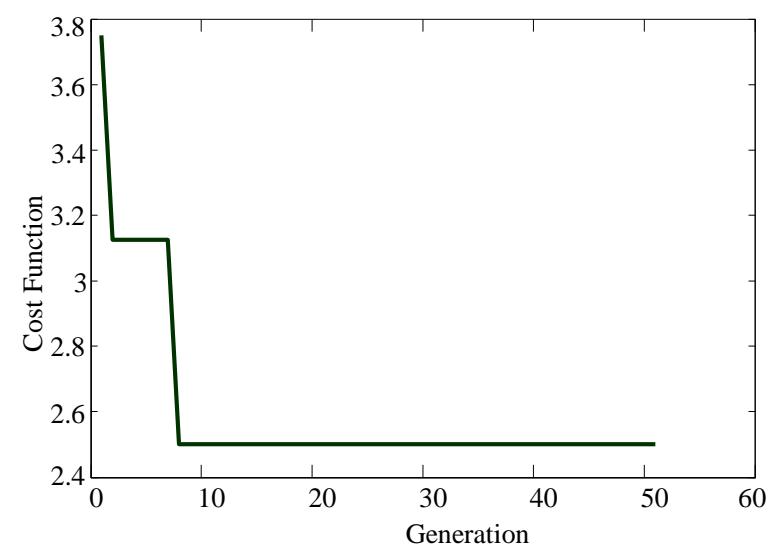

Figure 7. Cost function for constant step function.
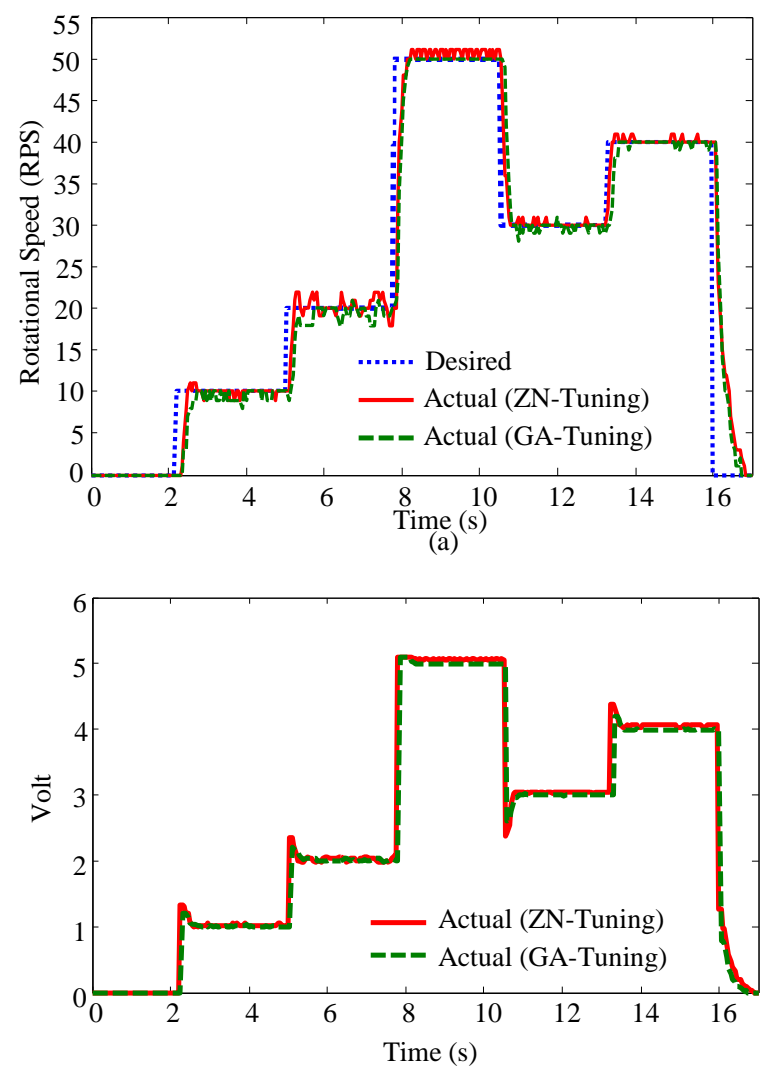

(b)

Figure 8. Varying step function (a) control response (b) control action. 


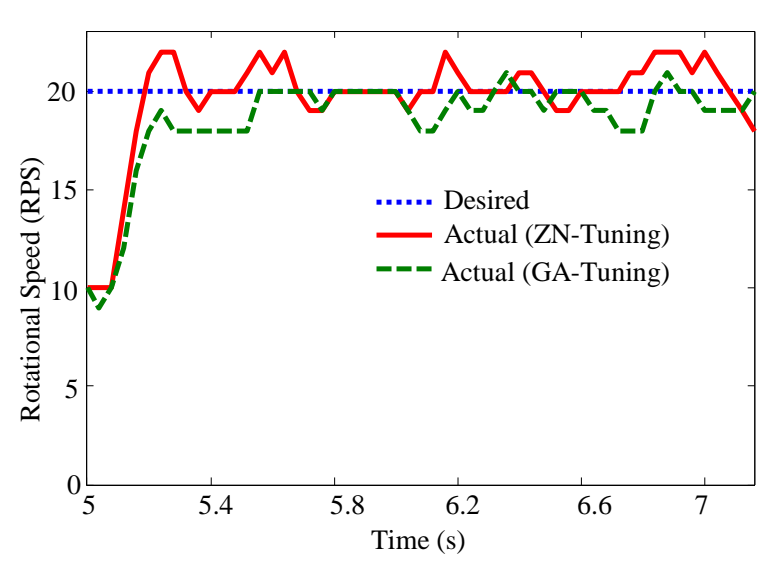

(a)

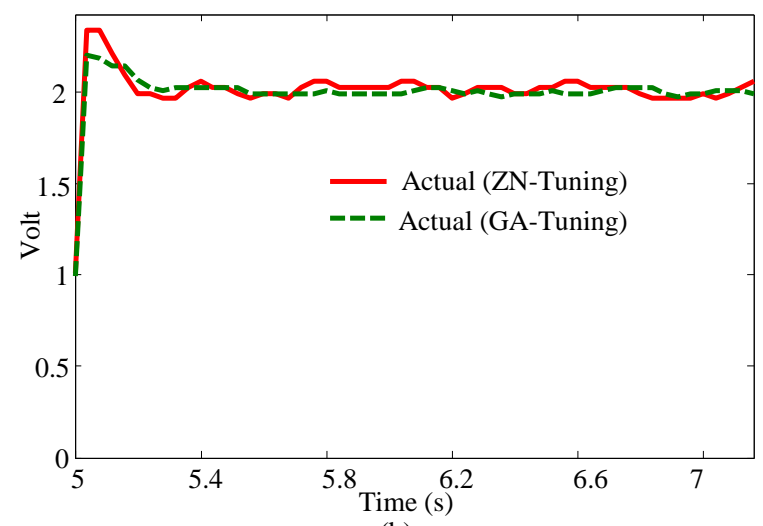

(b)

Figure 9. Time window of 5-7 s, (a) control response (b) control action.

depicted in Figure 9. Details of performances and the gains of each controller are tabulated in Table 5 and Table 6, respectively. Under varying step function, PD controller optimized by GA produces a cost function as shown in Figure 10. It displays the cost function with respect to the number of iterations. As observed, the cost converges straightforward after the- $3^{\text {rd }}$ iteration and is steady to a certain value exhibits.

TABEL 5

CONTROLLER'S PERFORMANCES UNDER VARYING STEP FUNCTION

\begin{tabular}{lcc}
\hline Performance & ZN-PD & GA-PD \\
\hline Rise time (s) & 0.08 & 0.17 \\
Settling time (s) & 2.69 & 2.69 \\
Overshoot (\%) & 22.22 & 5.00 \\
Peak time (s) & 0.30 & 1.70 \\
\hline
\end{tabular}

TABEL 6

GAIN OF CONTROLLERS FOR VARYING STEP FUNCTION

\begin{tabular}{ccc}
\hline \multirow{2}{*}{ Controller } & \multicolumn{2}{c}{ Gain } \\
\cline { 2 - 3 } & $\mathrm{P}$ & $\mathrm{D}$ \\
\hline ZN-PD & 1.58 & 0.4 \\
GA-PD & 0.85 & 0.02 \\
\hline
\end{tabular}

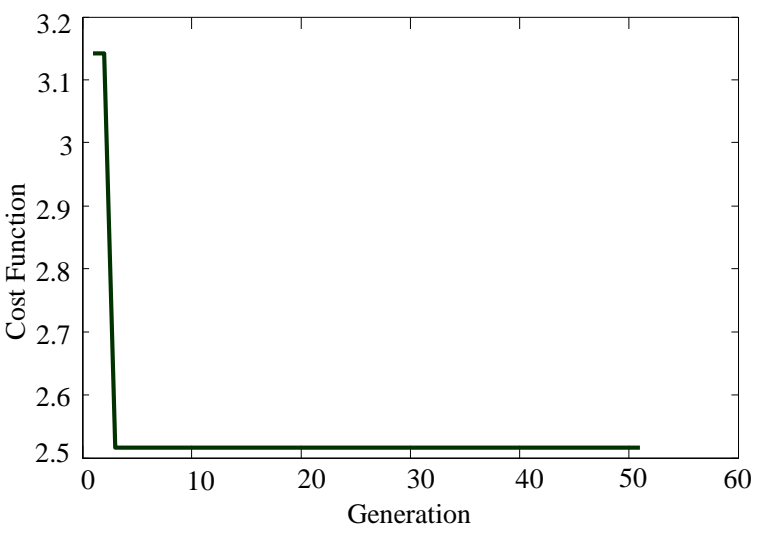

Figure 10. Cost function for varying step function.

\section{CONCLUSION}

In this paper, a controller namely the GA-PD is proposed for controlling the BLDC motor in real-time implementation. Results show that the proposed controller can improve the performance of closed-loop control system under constant and varying step functions. Important conclusions and suggestions from this work are derived below.

- $\quad$ The GA-PD controller make the tuning process of the gains of PD controller much more easily.

- The GA-PD controller outperforms the ZN-PD controller in terms of fast settling time and minimum overshoot, while the latter has faster rise time than the earlier. However, under constant step function, the fast rise time of ZN-PD controller results in overshoot of $6.67 \%$. The overshoot increases into $22.22 \%$ under varying step functions.

- The gains of the ZN-PD controller are higher than the GA-PD controller, where it leads to high control actions and fast rise time.

- The cost functions resulted under constant and varying step functions show a quick convergence.

- In the future, further research need to be conducted in the field of BLDC motor speed controlling using other method to obtain better performance.

\section{ACKNOWLEDGEMENT}

Research facility for this work from Research Centre for Electrical Power and Mechatronics, Indonesian Institute of Sciences is gratefully appreciated.

\section{REFERENCES}

[1] K. Premkumar and B.V.Manikandan, "Adaptive neuro-fuzzy inference system based speed controller for brushless DC motor", Neurocomputing, vol. 138, pp. 260-270, 2014.

[2] K. Premkumar and B.V.Manikandan,'Speed control of BLDC motor using bat algorithm optimized adaptive neuro-fuzzy inference system", Applied Soft Computing, vol. 138, pp. 260270, 2015.

[3] K. Premkumar and B.V.Manikandan, "Fuzzy PID supervised online ANFIS based speed controller for brushless DC motor", Neurocomputing, vol. 157, pp. 76-90, 2015.

[4] A.A. El-Samahy and M.A. Shamseldin, "Brushless DC motor tracking control using self-tuning fuzzy PID control and model reference adaptive control", Ain Shams Engineering Journal, In Press, pp. 76-90, 2016. 
[5] M. Tariq, et al., "Fast response antiwindup PI speed controller of brushless DC motor drive: modelling, simulation and implementation on DSP", Journal of Electrical Systems and Information Technology, vol. 3, pp. 1-13, 2016.

[6] E. Gowthaman, et al., "Speed control of permanent magnet brushless DC motor using hybrid fuzzy proportional plus integral plus derivative controller", Energy Procedia, vol. 117, pp. 1101-1108, 2017.

[7] H.E.A. Ibrahim, F.N. Hassan, and A.O. Shomer, "Optimal PID control of a brushless DC motor using PSO and BF techniques", Ain Shams Engineering Journal, vol. 5, pp. 391398, 2014.

[8] S. Zhang and Y. Wang, "The simulation of BLDC motor speed control based-optimized fuzzy PID algorithm", in Proc. IEEE International Conference on Mechatronics and Automation, 2016, pp. $287-292$.
[9] A. Varshney, D. Gupta, and B. Dwivedi," Speed response of brushless DC motor using fuzzy PID controller under varying load condition", Journal of Electrical Systems and Information Technology, vol. 4, pp. 310-321,2017.

[10] J. Joy, and S. Ushakumari, "Performance comparison of a sensorless PMBLDC motor drive system with conventional and fuzzy logic controllers", Procedia Technology, vol. 25, pp. 643651, 2016.

[11] KC AXHM5100 BLDCM user manual, Oriental Motor, 2014.

[12] E. Yazid, M.S. Liew, S. Parman, and V.J. Kurian, "Improving the modelling capacity of Volterra model using evolutionary computing methods based on Kalman smoother adaptive filter", Journal of Applied Soft Computing, vol. 35, pp. 695-707, 2015. 